\title{
What Does 'Recovery' Mean to People with Neck Pain? Results of a Descriptive Thematic Analysis
}

\author{
David M. Walton ${ }^{*}, 1$, Joy C. MacDermid ${ }^{2}$, Todd Taylor ${ }^{3}$ and ICON ${ }^{\S}$ \\ ${ }^{I}$ School of Physical Therapy, Western University, London Ontario, Canada \\ ${ }^{2}$ School of Rehabilitation Sciences, McMaster University, Hamilton Ontario and, Clinical Research Lab, Hand and \\ Upper Limb Centre, St. Joseph's Health Centre, London Ontario, Canada \\ ${ }^{3}$ LifeMark Physiotherapy, London Ontario, Canada
}

\begin{abstract}
Objectives: To describe the meaning of being recovered as perceived by people with chronic mechanical neck pain.

Methods: To determine the way people with neck pain would describe a recovered state a descriptive thematic approach was used. A nominal focus group technique, written reflections, and one-on-one semi-structured interviews were used to collect sufficient data. Data from the focus groups were analyzed both through vote tallying and thematic analysis. Reflections and interviews were analyzed thematically by two independent researchers. Triangulation and memberchecking were employed to establish trustworthiness of results.

Results: A total of 35 people, primarily females with neck pain of traumatic origin, participated in this study. Thematic analysis identified 6 themes that adequately described the data: absent or manageable symptoms, having the physical capacity one ought to have, participation in life roles, feeling positive emotions, autonomy \& spontaneity, and reestablishing a sense of self. Member checking and triangulation suggested data saturation and accuracy of the generated themes.

Discussion: Recovery from neck pain appears to be informed by factors that fit with existing models of health, quality of life and satisfaction. Basing recovery solely on symptom or activity-level measures risks inaccurate estimates of recovery trajectories from traumatic or non-traumatic neck pain.
\end{abstract}

Keywords: Focus groups, qualitative, whiplash, thematic analysis.

\section{INTRODUCTION}

Mechanical neck pain is one of the most common musculoskeletal complaints, with an estimated 1-year period prevalence of $1 / 3$ to $1 / 2$ of adults in the United Kingdom and North America $[1,2]$. Both specific (ie. trauma-related) and non-specific neck disorders have been associated with a spectrum of signs and symptoms, including neck or shoulder girdle pain, stiffness, tenderness, headaches, radicular symptoms, concentration or sleep difficulties, and anxiety,

*Address correspondence to this author at the Rm. EC1443, School of Physical Therapy, Western University, 1201 Western Rd., London, ON, N6H 1A1, Canada; Tel: 519-661-2111, Ext. 80145; Fax: 519-661-3866; E-mail: dwalton5 @ uwo.ca

${ }^{8}$ International Collaboration on Neck

ICON is a multi-disciplinary collaborative group that includes scientist-authors (listed below) and support staff (Margaret Lomotan) that conducts evidence synthesis, qualitative inquiry and knowledge translation aimed at reducing the burden of neck pain; ICON is funded by the Canadian Institutes of Health Research.

The ICON authors include (in alphabetical order): Gert Bronfort, Norm Buckley, Lisa Carlesso, Linda Carroll, Pierre Côté, Jeanette Ezzo, Paulo Ferreira, Tim Flynn, Charlie Goldsmith, Anita Gross, Ted Haines, Jan Hartvigsen, Wayne Hing, Gwendolen Jull, Faith Kaplan, Ron Kaplan, Helge Kasch, Justin Kenardy, Per Kjær, Janet Lowcock, Joy MacDermid, Margareta Nordin, Paul Peloso, Jan Pool, Duncan Reid, Sidney Rubinstein, P. Lina Santaguida, Anne Söderlund, Natalie Spearing, Michele Sterling, Grace Szeto, Robert Teasell, Arianne Verhagen, Howard Vernon, Dave Walton, Marc White. All members provided direction to this project; some members provided instrumental help in conduct of this project. All ICON members contributed to writing this manuscript (review/revise) and approved the manuscript. among others [3,4]. Neck pain is best characterized as multifactorial and episodic in nature, with an often unclear etiology [5]. Trauma, specifically whiplash associated disorder (WAD), appears to be one of the most common mechanisms for developing chronic neck pain [6]. While rates of recovery vary widely [7], a recent estimate drawn from a large literature review, suggests that approximately $50 \%$ of acute WAD sufferers will continue to report symptoms after 1 year [8].

Given the high rate of chronic problems in persons with neck pain, prognostic studies play a potentially important role in optimizing intervention. The identification of individuals at 'high risk' in the acute stage of symptom onset could lead to the development and implementation of targeted secondary prevention strategies that may mitigate the transition to chronicity. However, consensus on the most important prognostic factors has been elusive, in part owing to a lack of consensus on the outcome(s) that is/are to be predicted. Our previous systematic review showed that there was very little agreement in the prognostic literature on how 'recovery' from traumatic neck pain had been operationalized [7]. The most common approaches to operationalize a state of 'recovery' are through the use of symptom intensity scales, region-specific disability indices (such as the Neck Disability Index (NDI) [9]), or work status. While each 
method possesses a level of validity for identifying recovery, each also has limitations. Attempts to develop more multidimensional [10] or patient-informed [11] scales have been reported. While these newer scales appear to function well as measurements of change over time, the appropriate criteria for what should be considered a 'recovered' state for the purposes of prognostic research remain elusive. Further clouding the definition of recovery, opinions vary on whether there are in fact any chronic residual symptoms from a single episode of neck pain, or whether sufferers have recurrent episodes which should be considered unique unto themselves. [2, 12] As a result, patients, third-party health funders, and clinicians might have difficulty defining recovery. The variety of definitions of recovery observed in the literature renders data syntheses across studies difficult to conduct.

Knowledge can be accumulated through both quantitative and qualitative approaches. Well-designed qualitative studies have the ability to provide rich information for questions that are less well-defined or about which little is known, such as "what constitutes recovery to the injured person?" For example, Beaton and colleagues [13] used a groundedtheory approach to determine what it means to be 'better' amongst a group of people who had recovered from repetitive strain injuries in the upper extremity. From this research they propose a theory that the perception that one is 'better' might be influenced by three sub-constructs: symptom resolution, readjustment to limitations, or redefinition of the concept of health. These findings were similar to those of Hush and colleagues [14], who used a thematic framework approach to identify the meaning of recovery for people with low back pain, with three broad themes that centred around symptoms, functional capacity and quality of life. Traditional operationalizations for recovery tend to favour measures of symptom resolution alone, often neglecting the latter two sub-constructs. Research of this nature should influence the development of new patient-reported outcomes (PROs). With regards to the specific condition of neck pain, irrespective of whether the pain is classified as traumatic or otherwise, the identification of important domains for recovery from the patient's perspective has yet to be adequately explored. A more comprehensive understanding of 'recovery' will strengthen the development and interpretation of new or existing outcomes in prognostic and intervention studies.

The primary purpose of this study was to determine the domains of recovery as described by people with mechanical (specific or non-specific) neck pain. A combination of focus groups, written reflections, and one-on-one interviews were used to obtain saturation and allow for triangulation of results. We used a thematic qualitative approach drawn from traditional descriptive approaches $[15,16]$. This approach is appropriate when a description of a lived experienced is required, about which little is formerly known and provides a framework for describing experiences in concrete, everyday language.

\section{METHODS}

\section{Data Collection}

In contrast to quantitative approaches, qualitative research recognizes that the researcher cannot be separated from his or her interpretation of the data that are collected. Journaling and reflection upon pre-conceived beliefs identify the researcher's position and values that interact dynamically with the data analysis, and should therefore be transparent. As a preliminary reflexive step in the process, we constructed a theoretical framework for the nature of recovery that clearly outlined our opinions on the matter, suggesting that happiness or satisfaction were more appropriate constructs for capturing recovery than are symptom intensity or structured disability scales [17].

Data collection began with a series of three focus groups using a nominal group technique [18] as an efficient means of generating a large volume of data. Participants were recruited through posted flyers (convenience sampling) or word of mouth (snowball sampling) in local rehabilitation (physiotherapy or chiropractic) clinics. Each focus group included between 4 and 6 informants and lasted approximately 90 minutes. After provision of basic demographic data and completion of the Neck Disability Index [9], the session started with the posing of a nominal question: How will you know when you are recovered? That is, how will the recovered version of you differ from the current version of you? As per the protocol described by Delbecq [18], the session began with 10 minutes of quiet individual reflection, followed by a round-robin sharing of ideas until all ideas had been shared and adequately described. Each of the ideas recorded are discussed by the focus group and collapsed with other like ideas where applicable, such that each of the final ideas were deemed by the participants to be unique constructs. Independent, anonymous ranking allowed each member to identify the top five most important ideas. All ideas from each of the focus sessions were documented and retained verbatim for thematic analysis.

In an attempt to improve trustworthiness of results through triangulation from different data collection methods, independent semi-structured one-on-one interviews were conducted and analyzed thematically. Informants were recruited from samples of participants in previous research studies, 16 from Canada and 3 from Australia. Informants were targeted based on their perceived ability to provide rich, detailed data on the question at hand using a maximum variability sampling approach (from severely disabled to near or recently recovered). Recruitment ceased once saturation appeared to have been reached. Each interview was conducted either in person or by phone using a semistructured interview guide, and included questions pertaining to their experience of neck pain, their experience of treatment for that pain, and beliefs about the nature of recovery. Only the latter section of the interview was analyzed for this manuscript. The questions and probes were used by 1 of 4 experienced qualitative researchers to define answers to the question: How will the recovered version of you differ from the current version of you? Probing questions were used where necessary to achieve adequately comprehensive data. Interviews were recorded and then transcribed verbatim. Any informants who were unable to participate in either the focus sessions or interviews were posed the same question and invited to submit written personal reflections on the matter, which were then analyzed the same way. All data collection procedures were approved by the relevant institutional research ethics board prior to 
initiation and all participants provided informed, written consent to participate.

\section{Analysis}

Data derived from the focus sessions were analyzed in two forms: by a simple tally of the ranking each idea received within each focus group to identify the top five, and through descriptive thematic analysis. Descriptive thematic analysis occurred according to Sandelowski $[15,16]$. This involved two researchers (DW \& TT) who independently reviewed the data and identified thematic content that could be coded using an iterative process. Rather than assigning $a$ priori codes, new codes were generated by the data. As new codes emerged, they were checked for redundancy with previous codes. This process of code generation, checking, re-checking and confirmation drove the analysis. The researchers met to arbitrate any disagreement with coding. Meta-themes were identified from the list of codes generated, and representative quotes were identified to describe each theme. Recorded one-on-one interviews and written reflections were transcribed and encoded in the same fashion by two independent researchers (DW \& JM).

\section{Trustworthiness of the Data and Findings}

Qualitative research is not meant to be externally valid in the same way that quantitative research is, but it should accurately reflect the perceptions and experiences of the informants. To verify the trustworthiness of the data, the identified themes and quotes were reviewed by the study participants ('member checking') by providing interested participants $(n=6)$ with the themes generated and soliciting feedback on the clarity and accuracy of such. Further, feedback on the themes was requested from clinicians and academics of the International Consensus on Neck Pain (ICON) group, an international, interdisciplinary group of knowledge experts in the field of neck pain. Feedback from patients and knowledge experts was used to revise or modify the themes as appropriate. The final themes were approved and accepted by the ICON group.

\section{RESULTS}

A total of 12 participants took part in one of three focus sessions, four written reflections were submitted by eligible participants who could not attend a session, and 19 face-to- face interviews were conducted, for a total of 35 informants. The age interval was wide, varying from 18 to 65 years, and the majority were experiencing chronic neck pain of traumatic origin (Table $\mathbf{1}$ ).

The focus groups generated 103 indicators of recovery across the three sessions. The results of the focus group voting process, with the top 5 indicators by group, are shown in Table 2. Issues concerning activity limitation and participation in life roles were represented in all three groups. Each group also voted for the absence of pain-related emotional distress, in terms of fear, anxiety or general life enjoyment, as a key indicator of recovery. Social reconnections, specifically enjoyment of intimate connections with spouse and family, were the top indicators for 2 out of 3 groups. Other indicators included vitality (energy to work and still enjoy socializing), independence (less financial stress, freedom from medications) and a general re-engagement with life (fulfill roles, make new goals for the future).

All 103 items from the focus sessions were coded along with the transcripts from the face-to-face interviews and the reflective pieces. Themes were identified that best represented the variety of codes generated, and representative quotations were found to describe the themes in conversational terms. Member checking revealed that the themes generated accurately reflected the perspectives of the participants. These themes are described below.

\section{Absent, or at Least Manageable, Symptoms}

Reduction of symptoms was an almost universal indicator of recovery in our participants. The types of symptoms that were of concern could be broadly grouped into neck pain and other symptoms. Other symptoms included headaches, facial pain, dizziness, nausea, ringing in the ears, blurred vision, concentration difficulties, visual disturbances, sleep disturbances, slowed cognition, neck stiffness, weakness, and numbness or tingling about the neck or arms. Whether in reference to pain or other symptoms, informants indicated that reduced intensity and frequency would be key indicators of recovery:

$$
\begin{aligned}
& \text { "I would feel better because I am not in pain } \\
& \text { anymore." }
\end{aligned}
$$

Table 1. Characteristics of the Participants

\begin{tabular}{|l|c|c|c|}
\hline & Focus Groups & Interviews & Written Reflections \\
\hline \hline $\mathrm{N}$ & 12 & 19 & 4 \\
\hline Age (range) & $49(38-60)$ & $33(20-69)$ & $51(46-59)$ \\
\hline$\%$ Female & $50 \%$ & $79 \%$ & $75 \%$ \\
\hline Symptom duration* (range) & $39(2-144)$ & $107(6-636)$ & $40(2-98)$ \\
\hline Employment status (\%) & $17 \%$ & $16 \%$ & $25 \%$ \\
Full - Time & $17 \%$ & $11 \%$ & $0 \%$ \\
Part - Time & $67 \%$ & $62 \%$ & $75 \%$ \\
Unemployed / Disability & $0 \%$ & $0 \%$ \\
Student & $54 \%(12-84)$ & Not available & $62 \%(60-64)$ \\
\hline Neck Disability Index (range) & & \\
\hline *. mean symptom duration in months & & \\
\hline
\end{tabular}


Table 2. Top 5 Most Important Indicators of Recovery, as Voted on by the Informants of Each Focus Session

\begin{tabular}{|c|c|c|}
\hline $\begin{array}{l}\text { GROUP } 1 \\
\text { Mean NDI*: } 82 \% \\
\text { Mean Duration: } 59 \text { Months } \\
\text { Mean Age: } 56.5 \text { y.o. }\end{array}$ & $\begin{array}{l}\text { GROUP } 2 \\
\text { Mean NDI": } 32 \% \\
\text { Mean Duration: } 20 \text { Months } \\
\text { Mean Age: } 48.5 \text { y.o. }\end{array}$ & $\begin{array}{l}\text { GROUP } 3 \\
\text { Mean NDI" } 55 \% \\
\text { Mean Duration: } 39 \text { Months } \\
\text { Mean Age: } 42.5 \text { y.o. }\end{array}$ \\
\hline $\begin{array}{l}\text { 1. Enjoying Intimacy } \\
\text { 2. Finding the will to make new goals for } \\
\text { the future } \\
\text { 3. Being able to perform the necessities of } \\
\text { everyday life } \\
\text { 4. Less financial stress } \\
\text { Finding enjoyment in socializing with } \\
\text { others (who are non-injured) }\end{array}$ & $\begin{array}{l}\text { 1. Be rid of symptoms } \\
\text { 2. No fear, worry or hesitation when doing } \\
\text { basic things } \\
\text { 3. Feel more comfortable driving } \\
\text { 4. Return to "pre-accident" life, fulfill roles } \\
\text { 5. Have energy to work and still enjoy } \\
\text { leisure time/socializing }\end{array}$ & $\begin{array}{l}\text { 1. Strengthen connections with immediate } \\
\text { family (spouse, children) } \\
\text { 2. Able to shovel snow, drive long distances, } \\
\text { mow lawn, carry children, run, exercise } \\
\text { without worrying about after effects } \\
\text { 3. Mood improved, less psychological distress } \\
\text { (depression, anxiety, PTSD) } \\
\text { 4. Would be free from medication } \\
\text { 5. Could manage pain, keep it under control, } \\
\text { decrease interference with daily life }\end{array}$ \\
\hline
\end{tabular}

*: Neck Disability Index

'Reduced symptoms' was in the top five indicators of recovery in two of the three focus groups. However, reduction didn't necessarily mean abolishment, as many informants indicated that a change in the frequency or quality of their pain could also indicate recovery:

"But it is still more the frequency than the actual pain... I think I would be the same, just not as uncomfortable."

One informant observed that abolishment was not a realistic indicator of recovery, because she had some pain before her neck injury. For her, an indicator of recovery would be pain intensity similar to that experienced prior:

\section{"I expect to be back at the pain level I was} before all this started".

\section{Participation in Valued Life Roles}

Many participants indicated that their symptoms interfered with participation in valued life roles, the resumption of which would be a key indicator of recovery. Valued roles were identified both within and outside of the home. Roles within the home included being a parent, a spouse or family member, a bread winner, and someone who maintains general order (e.g. home maintenance). Interference with parenting was characterized by this quote:

"I guess with the kids, you've got to be careful when you're playing games with them and running around...I can't sit down for a long period of time with them looking down and helping them with their work"

Participants recognized their role as a contributing or participating spouse or partner was a key indicator of recovery, expressed through quotes such as

"I would feel better if I didn't have to rely so much on my husband to do things" and "I could enjoy intimacy again”.

Roles outside of the home included being a productive worker, trusted friend or dependable community member. Work status was an infrequent indicator of recovery, and was described more in terms of stamina or symptoms:
"I would be able to work an entire day and not pay for it later" and "I could do all my work duties and still have the energy left for other things I want to do afterwards"

Such quotes suggest that these respondents fit the label of the 'working disabled', where they were able to fulfil their work responsibilities but little else.

Being a trusted friend was characterized by this quote:

"I would be able to enjoy, you know, hanging out with my friends who aren't injured and have them understand that when I say I can't go and do something with them, it's that I really can't. I'm not just being a whiner. Sometimes I don't think they really understand."

Another participant stated that he would feel recovered when:
“...my friends actually call me to go and do something with them. Right now it's always me doing the calling. I don't think they really enjoy spending time with me because maybe they think I bring the whole group down or something."

Both of these participants expressed a sense of social isolation, the resolution of which would indicate a sense of recovery.

\section{Having the Physical Capacity One Ought to Have}

Participants identified a number of activity-level limitations that they believed they ought to be able to do, when compared to other people of their age and sex. Examples were shoveling snow, driving long distances, mowing the lawn, carrying or playing with children, shopping for groceries, and performing general exercise. This theme was characterized by the quote:

\section{"I would be able to do the kinds of things any normal 45-year-old man could do"}

This comment suggests that this participant was conducting some form of comparison with what he perceived 
were physical norms for his age and gender. Performance of 'normal' activities was in the top 5 indicators of 2 of the 3 focus groups.

Physical capacity was also expressed in terms of impairment-level concerns. Many respondents described specific movements, such as turning the head or raising the arm, that they could not do or that caused them pain. While not described in terms of specific activities, resolution of these more general movement impairments was seen by many as a key indicator of recovery:

"I'd love to be able to bend over easily, or to reach up with my hand over my head. I've learned not to do those things."

\section{Feeling Positive Emotions}

Participants used several adjectives to describe their negative moods, including grumpy, cranky, crabby, moody or being in 'the worst mood'. A general improvement in mood was a common indicator of recovery, without necessarily being directly tied to symptoms:

"Get out, put a smile on, ask other people how they are"

Of note here was that participants did not indicate that they must be happy all the time, but that they found the emotional lability associated with symptoms, lack of sleep, stress from their medicolegal involvement or financial pressure, to be interfering with their sense of wellness. Participants believed their negative emotions were a result of other sequelae rather than a direct symptom of their neck problems. If they were feeling generally happier, it would be an indicator that those pressures had been resolved. An example was this quote:

"I probably wouldn't be so grumpy in the morning and when my neck hurts. You know, happier."

Some participants described emotional or cognitive states that could best be labeled as catastrophizing, characterized by this quote from a participant who believed that changing her perspective on her pain condition facilitated her perception of being almost fully recovered:

"I try not to look on every pain episode as the end of the world because I initially did that. I'd go 'Oh my god, this is it, I'm dying. What am I going to do now?',

To this participant, more positive beliefs about her pain were associated with her sense of recovery.

\section{Autonomy and Spontaneity}

One of the most consistent themes for indicating recovery was that participants wanted to regain their selfperceptions as an autonomous human being. Almost universally participants indicated that they would feel recovered when they no longer have to plan their lives around medication schedules, doctor's visits, lawyer visits, rehabilitation sessions, independent examinations and symptom fluctuation. As one participant put it:

\begin{abstract}
"I won't have to be constantly planning about how to go about my daily routine. So I wouldn't have to do that. I'd be able to be more spontaneous and if I want to paint the spare room, I'll paint the spare room."
\end{abstract}

Many participants also spoke in terms of being 'slaves' to their symptoms, that they were either unpredictable and therefore interfered with a sense of spontaneity, or were predictable and demanded careful planning. Autonomy was described in terms of being less reliant on the medical system for management of their condition, or friends and family members to accomplish tasks. One participant whose condition necessitated assistive devices in the home felt that these were an obtrusive, constant reminder of her reliance on external aids and that being rid of such things would be an important indicator of recovery.

Many of the participants who were involved in medicolegal disputes described a lack of autonomy in terms of feeling the constant sense of being monitored. As one such participant put it:

\section{"There are times when I'd like to go outside and just try doing some work in the garden, but I don't dare do it because you never know when someone's hiding in the bushes across the street with a video camera."}

Many participants described financial pressures as robbing them of a sense of autonomy or spontaneity. In most cases, these pressures were a result of loss of income, but in some cases they were a result of expenses related to legal costs, rehabilitation, or medications. While all participants recognized that some financial pressure was a natural part of life, the resolution of the additional expenses related specifically to their pain or injury would be a key indicator of recovery.

\section{Re-Establishing a Satisfactory Sense of Self}

Many participants indicated that they did not 'feel like themselves', as they were absorbed in their pain-related limitations and could not move forward with their personal development. Recovery meant shedding their self-perceived identity of a 'person in pain'. They identified the difficulty with making firm plans, and thereby an uncertain future. As one participant who considered herself nearly recovered described her lack of clear direction:

\section{"I don't even know what I was doing, I was wandering around in a daze."}

Goal setting was identified as a challenge for many, and a clearer sense of their potential for achievement was identified as an important indicator of recovery for some:

\section{"I would have the will to actually make new goals for the future again."}

Some participants recognized that a full return to their pre-injury status was unreachable, and so indicated that recovery could mean adapting to a new definition of 'normal' and still being satisfied. One participant who was involved in academia, observed: 
"I don't think that there will ever be a time that I can be at the computer as much as I need to for academia, not do any treatment or not do any other maintenance and not expect to have pain."

This suggests that some participants were willing to accept a new reality, one in which maintaining activity or participation required some kind of intervention, but still feel as though they had regained the potential for success and personal satisfaction that indicated recovery.

The subtheme of 'readjustment and acceptance' was evident from several of the participants. Many indicated that having a firm sense of what they could and couldn't do, not just due to their neck pain but also due to other age- or activity-related comorbidities, would provide a sense of selfconfidence and recovery. One particularly descriptive quote summarized this theme nicely:

\section{"I mean, I'm so careful now, I was never this [sic] careful. I'm careful about things that I do because I'll pay for it and I feel, I'm angry and frustrated that I can't do certain things so if we could take that away, I wouldn't feel so...It's been a bit of a shock to my ego, not being able to do things means I feel like I have to make excuses and I don't want to tell people the story and it feels like I'm not as good a person, I'm not as strong as I used to be. It gets very complicated but if I didn't have this pain and these limitations I would just feel like a more confident person."}

This quote describes what appears to be a common sense of frustration the participants felt over the loss of their perceived selves. This participant appeared to indicate that her genuine self was a confident and strong person, and regaining those qualities would help her feel recovered. Being aware of limitations, but satisfied with the self, based on perceived current and future potential, permeated comments assigned to this theme.

Many of the participants recognized that, while they may not be the same person they were prior to the onset of their neck pain, they could still feel recovered if they were able to accept their current set of limitations and potential. For some this meant re-establishing life goals, for others it meant finding the positive in what was a generally negative experience:

\begin{abstract}
"Feels to me like it's humpty dumpty fell off the wall, and even though I didn't have breaks everywhere, it was just enough to turn my life upside down. I see now the benefit of all of that. It slowed me down enormously and it made me listen. I listen to my body now and that's so important."
\end{abstract}

\section{Member Checking}

A total of 6 participants from the focus groups and interviews volunteered to review the themes for clarity and accuracy, and feedback was actively solicited from the ICON group. This process resulted in revision of the label of the 'ought functional capacity' theme, but no change in the number (greater or fewer) of themes was suggested. Both the participants and knowledge experts accepted the final themes as described here.

\section{DISCUSSION}

Using a descriptive thematic analysis approach we identified that recovery according to people living with neck pain is multidimensional; these dimensions range from symptom reduction to acceptance and re-engagement with the sense of self. Indicators of recovery included items that would fit well within the International Classification of Functioning, Disability and Health framework, including tissue structure and function, activity, and participation level concerns. Improved social interactions, being free of stigma, being viewed as credible, and re-establishment of a firm trajectory for personal growth and future achievement were themes that provided rich knowledge of the expectations for recovery in this population.

The themes identified fit with previous theories on the nature of recovery, satisfaction and happiness. Ryan and Deci [19] describe happiness as being informed by 3 subthemes: autonomy, relatedness (social interaction) and competence (physical and cognitive capacity). These themes are mirrored in our findings, and suggest that people with neck pain are searching for happiness and satisfaction as much as they are full symptom resolution. The themes identified by Beaton and colleagues' [13] (resolution, readjustment and redefinition) and Hush and colleagues [14] (symptom attenuation, performance capacity and quality of life) could also be seen in the themes identified from our participants. Taken together, this body of work suggests that basing recovery status solely on symptom presence or absence could lead to considerable mislabelling.

Our participants, who represented a wide variability in disability experience as indicated by their NDI scores [9], identified several different symptoms and activity limitations. Few of these are included on currently-available neck-specific disability measures. However, these were not universally described by all participants, and this emphasizes an apparent weakness of many current approaches to measuring disability: the assumption that all items are equally important to all respondents. Further, we are currently unaware of any neck-specific measures that include items pertaining to intimate social relationships, sense of autonomy and spontaneity, or confidence with future potential. While it is not our intention to suggest the 'best' tool for measuring disability or recovery status for people with neck pain, based on our findings it appears that there may be a need for development of additional patient reported outcome measures. The development of these should allow a more patient-centered approach, providing some flexibility in how items are included or weighted to capture this variable perspective. These findings suggest that current standardized outcomes that have been used to determine whether treatments are effective may not have adequately represented recovery, and thus indirectly, treatment effectiveness. Valid assessment of treatment response is fundamental to our understanding of treatment effectiveness, and the lack of patient-centred instruments may contribute to the variability in effect sizes observed in current systematic reviews $[20,21]$. 
It should be noted that patient-generated and weighted scales do exist, such as the Patient-Specific Index for hip and knee-related disability [22], the MACTAR Patient Preference Disability Questionnaire for arthritic conditions [23], and the Canadian Occupational Performance Measure [24]. As described by Jolles and colleagues [25] however, completely patient-generated outcomes also possess disadvantages that hinder their routine use in clinical and scientific inquiry. The best approach for establishing recovery status has yet to be described.

There are limitations to this work that should be considered. While the focus group sessions were conducted, scored and coded by the same two researchers, the one-onone interviews were conducted by 4 different interviewers, only one of which was consistent between the two formats. It has been suggested that qualitative research requires full immersion in all stages of data collection in order for deep meaning to be extracted [26], and as such it is possible that some of the finer nuances of the respondent's behaviours may have been lost by the researchers coding the data. It was not our intention to perform deep structured analyses, but rather to provide a thematic description of the general perspectives of people with neck pain, and in that we believe we have exercised adequate rigour. The separate review of transcripts by two researchers and the use of triangulation and member checking provide confidence in the trustworthiness of our findings. Triangulation was confirmed by the similarity in themes obtained through three different modes of data collection: nominal group technique, written reflections, and one-to-one interviews. However, qualitative research is not easily generalizable, and readers should be aware that while other people with neck pain may hold similar views, the results described herein, from mostly females with chronic neck pain of primarily traumatic origin living in 1 of 2 industrialized countries, can only be confidently applied to our participants. Readers will note that we also did not formally collect current litigation or compensation status, although it was clear from the sessions that none of our participants were involved in active litigation at the time, while roughly half were receiving some form of wage indemnity benefit. It is possible that people with neck pain as a result of other, more insidious or less litigious mechanisms, of more acute duration or from lessdeveloped countries, may have different perspectives on recovery.

A final consideration is that the nature of this study, as a qualitative interpretation of participant's comments, cannot be used to describe cause-and-effect relationships. It is possible that negative emotions, social disconnection, loss of autonomy and dissatisfaction with the self are all driven by the presence of neck-related symptoms. Support for this argument comes from previous work, such as that by Wallis and colleagues [27] who showed that negative emotional valence (depression) improved following successful intervention to relieve the symptoms of chronic neck pain in a subset of that population. However, given the complexity of the experience of pain and the nature of recovery described by our participants, it seems overly simplistic to believe that all indicators of recovery would naturally occur through resolution of symptoms. Such a position can be neither supported nor refuted through the work described here, but our work does provide domains for measurement in future intervention studies.

\section{CONCLUSIONS}

Recovery from mechanical neck pain is a multidimensional construct, informed by symptom severity and quality, impairment, activity and participation-level interference, autonomy, spontaneity, and satisfaction with the sense of self. These themes fit with previous frameworks for understanding the nature of health, happiness and satisfaction, and suggest that the target of measurement for neck-related intervention needs to go beyond symptom intensity.

\section{CONFLICT OF INTEREST}

The authors confirm that this article content has no conflict of interest.

\section{ACKNOWLEDGEMENTS}

This work was supported by Canadian Institutes of Health Research (CIHR) grant FRN: KRS-102084.

Additional acknowledgements are provided to the following who volunteered additional supportive activities to this project: Liora Bliumkin and Janice Cheung for assistance in conducting interviews.

\section{REFERENCES}

[1] Croft PR, Lewis M, Papageorgiou AC, et al. Risk factors for neck pain: a longitudinal study in the general population. Pain 2001; 93(3): 317-25.

[2] Cote P, Kristman V, Vidmar M, et al. The prevalence and incidence of work absenteeism involving neck pain: a cohort of Ontario lost-time claimants. Spine (Phila Pa 1976) 2008; 33(4 Suppl): S192-8.

[3] Spitzer WO, Skovron ML, Salmi LR, et al. Scientific monograph of the Quebec Task Force on Whiplash-Associated Disorders: redefining "whiplash" and its management. Spine 1995; 20(8 Suppl): 1S-73S.

[4] Sterling M, Kenardy J, Jull G, Vicenzino B. The development of psychological changes following whiplash injury. Pain 2003; 106(3): 481-9.

[5] Guzman J, Hurwitz EL, Carroll LJ, et al. A new conceptual model of neck pain: linking onset, course, and care: the Bone and Joint Decade 2000-2010 Task Force on Neck Pain and Its Associated Disorders. Spine 2008; 33(4 Suppl): S14-23.

[6] Freeman MD, Croft AC, Rossignol AM, Centeno CJ, Elkins WL. Chronic neck pain and whiplash: a case-control study of the relationship between acute whiplash injuries and chronic neck pain. Pain Res Manag 2006; 11(2): 79-83.

[7] Walton D. A review of the definitions of recovery used in prognostic studies on whiplash using an ICF framework. Disabil Rehabil 2009; 31(12): 943-57.

[8] Carroll LJ, Holm LW, Hogg-Johnson S, et al. Course and prognostic factors for neck pain in whiplash-associated disorders (WAD): results of the Bone and Joint Decade 2000-2010 Task Force on Neck Pain and Its Associated Disorders. Spine 2008; 33(4 Suppl): S83-92.

[9] Vernon H, Mior S. The Neck Disability Index: a study of reliability and validity. J Manipulative Physiol Ther 1991; 14(7): 409-15.

[10] Rebbeck TJ, Refshauge KM, Maher CG, Stewart M. Evaluation of the core outcome measure in whiplash. Spine 2007; 32(6): 696702 .

[11] Pinfold M, Niere KR, O'Leary EF, Hoving JL, Green S, Buchbinder R. Validity and internal consistency of a whiplashspecific disability measure. Spine 2004; 29(3): 263-8.

[12] Hill J, Lewis M, Papageorgiou AC, Dziedzic K, Croft P. Predicting persistent neck pain: a 1-year follow-up of a population cohort. Spine 2004; 29(15): 1648-54. 
[13] Beaton DE, Tarasuk V, Katz JN, Wright JG, Bombardier C. "Are you better?" A qualitative study of the meaning of recovery. Arthritis Rheum 2001; 45(3): 270-9.

[14] Hush JM, Refshauge K, Sullivan G, De Souza L, Maher CG, McAuley JH. Recovery: What does this mean to patients with low back pain? Arthritis Rheum 2009; 61(1): 124-31.

[15] Sandelowski M. What's in a name? Qualitative description revisited. Res Nurs Health 2010; 33(1): 77-84.

[16] Sandelowski M. Whatever happened to qualitative description? Res Nurs Health 2000; 23(4): 334-40.

[17] Walton DM, Macdermid JC, Nielson W. Recovery from acute injury: Clinical, methodological and philosophical considerations. Disabil Rehabil 2010; 32(10): 864-74.

[18] Delbecq AL, Van de Ven AA, Gustafson DH. Group Techniques for Program Planning: A guide to nominal group and delphi processes. Middleton, WI: Green Briar Press 1986.

[19] Ryan RM, Deci EL. On happiness and human potentials: a review of research on hedonic and eudaimonic well-being. Ann Rev Psychol 2001; 52: 141-66.

[20] Gross AR, Hoving JL, Haines TA, et al. A Cochrane review of manipulation and mobilization for mechanical neck disorders. Spine 2004; 29(14): 1541-8.
[21] Kay TM, Gross A, Goldsmith C, et al. Exercises for mechanical neck disorders. Cochrane Database Syst Rev 2005; (3)(3): CD004250.

[22] Wright JG, Young NL. The patient-specific index: asking patients what they want. J Bone Joint Surg Am 1997; 79(7): 974-83.

[23] Tugwell P, Bombardier C, Buchanan WW, Goldsmith CH, Grace E, Hanna B. The MACTAR Patient Preference Disability Questionnaire--an individualized functional priority approach for assessing improvement in physical disability in clinical trials in rheumatoid arthritis. J Rheumatol 1987; 14(3): 446-51.

[24] Law M, Baptiste S, McColl MA, Opzoomer A, Polatajko H, Pollock N. The Canadian Occupational Performance Measure: An outcome measure for occupational therapy. Can J Occup Ther 1990; 57(2): 82-7.

[25] Jolles BM, Buchbinder R, Beaton DE. A study compared nine patient-specific indices for musculoskeletal disorders. J Clin Epidemiol 2005; 58(8): 791-801.

[26] van Manen M. Researching Lived Experience. Human Science for an Action Sensitive Pedagogy. $2^{\text {nd }}$ ed. London, ON: Althouse Press 1997.

[27] Wallis BJ, Lord SM, Bogduk N. Resolution of psychological distress of whiplash patients following treatment by radiofrequency neurotomy: a randomised, double-blind, placebo-controlled trial. Pain 1997; 73(1): 15-22. 